\title{
Systematic literature review of the complications of primary and secondary tracheoesophageal punctures in patients with laryngectomies for voice
}

\section{restoration Basil Khan, 4th year medical student, Shadaba Ahmed FRCS, ORL-HNS}

\section{INTRODUCTION}

The aim of this study is to provide a critical evaluation of the current literature on the complications of primary and secondary tracheoesophageal puncture (TEP) in laryngeal cancer patients who have had total laryngectomy (TL). This will be achieved by reviewing and collecting data from trials. The study also hopes to provide recommendations for future studies in order to help improve current guidance on management of voice restoration(VR) to maximise success rates and minimise complication rates.

Anatomy and physiology of voice. Figure 1 illustrates the anatomy of key structures involved in creating voice. Voice is made of two components; these are phonation and articulation. Phonation refers to "sound production at the larynx" ${ }^{2}$ whereas the latter describes the process by which clear speech is formed. ${ }^{2}$ Vocal folds are known to control the pitch of the sound. Figure 2 illustrates the glottis where the vocal folds can be found. Air flows from lungs (source) through the vocal cords (vibration) and then amplified and modified by the paranasal sinuses, pharynx, oral and nasal cavities. The production of distinct sounds is achieved by voluntary movements of the tongue, lips and cheeks. ${ }^{2}$

Laryngeal carcinoma. Cancer of the larynx is the most common form of head and neck cancers. ${ }^{4}$ In Europe there has been a slight decline in the incidence of laryngeal cancers in both males and females. ${ }^{5}$ Studies have shown that primary prevention strategies such as elimination

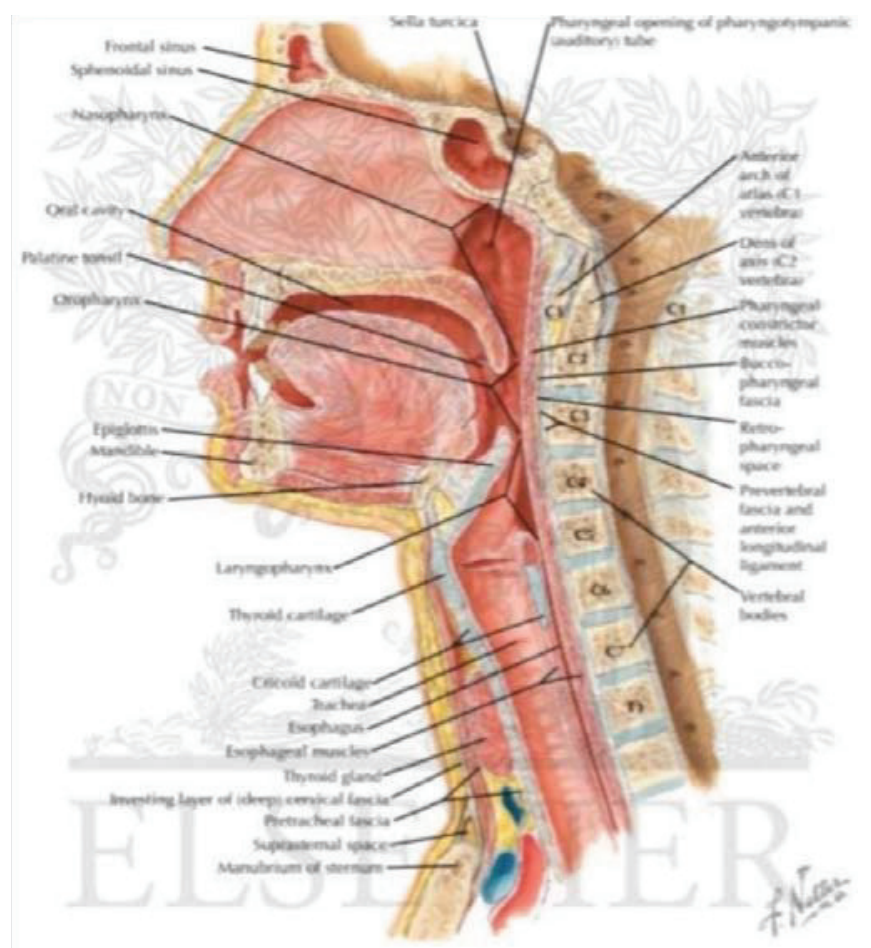

Figure 1: Anatomy of mouth and throat adapted from Netter images $^{1}$

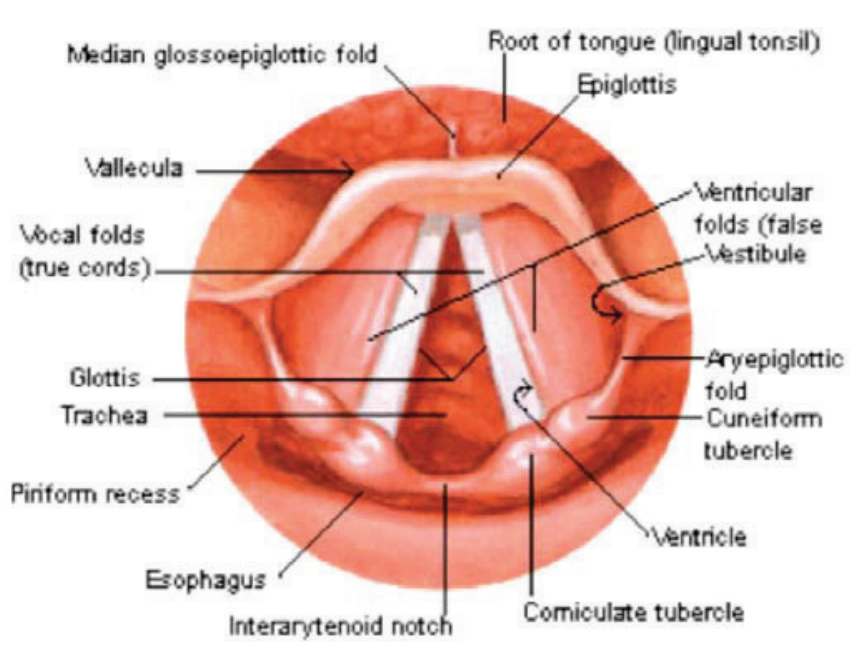

Figure 2: Entrance to glottis (cited from aboutcancer) ${ }^{3}$

of tobacco and reduction of alcohol have been the most effective methods of reducing the incidence of laryngeal cancers. ${ }^{6}$ There has also been a decline in the mortality rate of patients with laryngeal cancer. This is due to improvements in both the diagnostic and management aspects of laryngeal carcinoma. NICE pathways on upper aerodigestive tract cancers suggest that $\mathrm{T} 4 \mathrm{a}$ squamous cell carcinoma of the larynx is an indication for surgery with adjuvant radiotherapy with or without concomitant chemotherapy. ${ }^{7}$

Current guidance on laryngeal cancer. With recent advancements in surgical techniques organ preservation has become possible through methods such as partial laryngectomy, transoral laser microsurgery and transoral robotic surgery. ${ }^{4}$ Despite such advancements TL is still performed in advanced cases. TL was first done in 1873 by Christian Billroth however the current practice of the surgery follows the technique done by Bottini in $1875 .^{8}$ TL involves the complete removal of the larynx thus preventing natural air flow. In order to maintain an adequate flow of air the trachea is connected to a tracheal stoma which is located in the cervical region. The upper portion of the airway becomes disconnected with the lower hence leading to a loss of smell and voice. Indications for a TL include advanced laryngeal cancer, tumours of adjacent organs as well as post-traumatic laryngeal stenosis. ${ }^{9}$ The loss of speech presents numerous challenges to the patient and can have a detrimental effect on their quality of life. ${ }^{10}$

Tracheoesophageal punctures. Voice restoration (VR) is a key aspect of post-operative management in patients who have undergone TL. Non-surgical methods include electro larynx and oesophageal speech whereas surgical methods involve TEP followed by the placement of voice prosthesis. The latter has become the gold standard method of VR in patients. ${ }^{10}$ Thirty years following its introduction, TEP has become the first choice for voice restoration in patients who have undergone TL. Evidence 
has proved that this method of voice restoration leads to better speech intelligibility, longer phonation time and voicing. ${ }^{11,12}$ The procedure can be done at the time of TL (primary) or as a procedure separate from TL (secondary). TEP involves making a puncture through the posterior aspect of the trachea and anterior wall of the oesophagus. It is important that at the time of the procedure that the party wall has not been separated as this is a major contraindication to this procedure. ${ }^{11}$ Once the fistula has been created in the tracheoesophageal wall one-way valve prosthesis (VP) can be placed. ${ }^{10}$ This allows the air to be directed from the lungs into the oesophagus thus allowing vibrations in the wall to create sound. The VP also limits the entry of oesophageal contents in the trachea. ${ }^{13}$

Voice prosthesis. The mechanism of action largely revolves around the idea of shifting pulmonary air from the trachea and into the pharyngoesophagus allowing vibrations to create sound. This is achieved by the occlusion of the tracheostoma. VP can be divided into indwelling and non-indwelling. Non-indwelling VP are easier to manage and replace from the perspective of the patients. ${ }^{14}$ When deciding which one to place, factors such as ease and quality of speech, device life, the ability of VP to alleviate complications and cost of VP are all considered..$^{14}$ Current data suggests that indwelling VPs are widely preferred in practice, this is due a longer device life, reduced prosthesis-related complications and better speech quality. ${ }^{15}$

\begin{tabular}{|l|c|c|}
\hline Complication & $\begin{array}{c}\text { No. of patient } \\
\text { (out of 22) }\end{array}$ & $\%$ \\
\hline $\begin{array}{l}\text { Leakage around/ through } \\
\text { prosthesis }\end{array}$ & 14 & 64 \\
\hline Prosthesis displacement & 7 & 32 \\
\hline $\begin{array}{l}\text { Intractable aspiration of } \\
\text { secretions or oral intake }\end{array}$ & 5 & 23 \\
\hline $\begin{array}{l}\text { Bronchial aspiration of } \\
\text { prosthesis }\end{array}$ & 4 & 18 \\
\hline Granulation tissue & 3 & 14 \\
\hline Tracheostomal stenosis & 4 & 50 \\
\hline $\begin{array}{l}\text { Widening of } \\
\text { tracheoesophageal fistula }\end{array}$ & 18 \\
\hline
\end{tabular}

Table 1: Specific complications as reported by Dayangku Norsuhazenah et al (retrospective study in Malaysia looking at the complications and success rates of patients of patients undergoing TEP over a 10 year duration) ${ }^{19}$
Primary TEP has recently gained greater popularity. This is associated with earlier voice recovery which can be explained by the lack of need for nasogastric feeding following the procedure. ${ }^{16}$ Evidence shows that patients undergoing primary TEP can begin voice rehabilitation within 14 days of the procedure. ${ }^{16}$ Patients opting for primary TEP have the benefit of undergoing one less surgery. This leads to greater cost effectiveness. Even though these advantages provide a justification for setting primary TEP as the gold standard for voice restoration there is no guideline or set recommendation regarding the optimal time for carrying out this procedure. ${ }^{17}$ Certain evidence has shown that primary TEP is known to have a greater risk of complications. These include increased risk of infection, stomal stenosis, fistula and leakage from the prosthesis. ${ }^{17}$ Whereas secondary TEP involves greater costs it has been suggested that it may lead to fewer complications and greater patient satisfaction with the voice attained, especially after a period of aphonia. ${ }^{18}$

\section{RESULTS}

Tables 1 through to 11 are of results reported by the seven studies that have been selected for the purpose of this research. Tables 12 through to 14 have been created in order to provide a more meaningful comparison of the results observed across all seven selected studies.

\begin{tabular}{|l|c|c|}
\hline Surgical & \multicolumn{2}{|c|}{$\begin{array}{c}\text { Number of } \\
\text { reported cases }\end{array}$} \\
\hline Type of complication & Primary & Secondary \\
\hline Widening of fistula & 10 & 3 \\
\hline Stomal stenosis & 10 & 3 \\
\hline $\begin{array}{l}\text { Pharyngoesophageal } \\
\text { strictures }\end{array}$ & 6 & 1 \\
\hline
\end{tabular}

Table 2: Surgical complications in primary and secondary TEP reported By Cheng et al (retrospective study looking at patients undergoing TEP over a 16 year period. Patients who had a TL and TEP done between 1987 and 2002. Aim of study was to observe three common surgical complications mentioned above and three common prosthesis related complications mentioned below ${ }^{17}$

\begin{tabular}{|l|c|c|}
\hline Prosthesis related & \multicolumn{2}{|c|}{ Percentage of patients (\%) } \\
\hline Type of complication & $\begin{array}{c}\text { Primary } \\
(\mathrm{n}=51)\end{array}$ & $\begin{array}{c}\text { Secondary } \\
(\mathrm{n}=51)\end{array}$ \\
\hline Prosthesis leakage & 39.2 & 23.5 \\
\hline $\begin{array}{l}\text { Prosthesis } \\
\text { dislodgement }\end{array}$ & 11.8 & 5.9 \\
\hline
\end{tabular}

Table 3: Prosthesis-related complications in primary and secondary TEP reported by Cheng et al ${ }^{17}$ 


\begin{tabular}{|l|c|}
\hline $\begin{array}{l}\text { Prosthesis-related } \\
\text { complications }\end{array}$ & $\begin{array}{c}\text { Overall } \\
\text { percentage (\%) }\end{array}$ \\
\hline Leakage through valve & 51.8 \\
\hline Obstruction of prosthesis & 14.2 \\
\hline
\end{tabular}

Table 4: Prosthesis related problems across primary and secondary TEP as reported by Makitie et al (retrospective review of patients over 10 year duration. Patients between December 1992 and December 2002 with total laryngectomies and laryngopharyngectomies were selected for this trial) ${ }^{20}$

\begin{tabular}{|l|c|}
\hline Fistula-related complications & $\begin{array}{c}\text { Overall } \\
\text { percentage (\%) }\end{array}$ \\
\hline Inadequate size of prosthesis & 12.4 \\
\hline Granulation tissue in fistula & 9.2 \\
\hline Leakage around prosthesis & 7.3 \\
\hline Puncture site too high or too low & 4.1 \\
\hline Extrusion of prosthesis & 0.5 \\
\hline Stricture of tracheostoma & 0.5 \\
\hline
\end{tabular}

Table 5: Fistula-related complications across primary and secondary TEP as reported by Makitie et al ${ }^{20}$

\begin{tabular}{|l|c|c|}
\hline & \multicolumn{2}{|c|}{ Number of cases } \\
\hline & $\begin{array}{c}\text { Primary } \\
\text { TEP }\end{array}$ & $\begin{array}{c}\text { Secondary TEP } \\
\text { (observed after TL) }\end{array}$ \\
\hline $\begin{array}{l}\text { Pharyngocutaneous } \\
\text { fistula }\end{array}$ & 11 & 3 \\
\hline Microstoma & 3 & 1 \\
\hline $\begin{array}{l}\text { Peritracheostomal } \\
\text { infection }\end{array}$ & 4 & 0 \\
\hline Abscess & 2 & 0 \\
\hline
\end{tabular}

Table 6: Long term complications in primary and secondary TEP as reported by Boscolo-Rizzo et al (retrospective study evaluating patients who underwent the procedures between June 1998 and December 2004. Patients undergoing TL after May 1998 were given primary TEP whereas those having TL between January 1996 and May 1998 were given a secondary TEP. Patients received an indwelling Blom-Singer prosthesis followed by Provox 2 during rehabilitation) ${ }^{21}$

\begin{tabular}{|l|c|}
\hline Surgical complication & Secondary TEP (\%) \\
\hline $\begin{array}{l}\text { Tracheoesophageal fistula } \\
\text { enlargement }\end{array}$ & 19.1 \\
\hline Mediastinitis & 3.1 \\
\hline Para oesophageal abscess & 3.1 \\
\hline
\end{tabular}

Table 7: Surgical complications in patients with secondary TEP as reported by Imre et al (retrospective study of patients undergoing secondary TEP and VP only insertion between January 2006 and June 2011. All patients received a Provox indwelling VP) ${ }^{22}$

\begin{tabular}{|l|c|}
\hline $\begin{array}{l}\text { Prosthesis-related } \\
\text { complication }\end{array}$ & Secondary TEP (\%) \\
\hline Deglutition of prosthesis & 12.7 \\
\hline Leakage around prosthesis & 19.1 \\
\hline Granulation tissue formation & 4.2 \\
\hline
\end{tabular}

Table 8: Prosthesis-related complications in patients with secondary TEP and VP insertion only as reported by Imre et $a l^{22}$

\begin{tabular}{|l|c|c|c|c|c|}
\hline Complication & $\begin{array}{c}\text { Provox } \\
\mathbf{1}\end{array}$ & $\begin{array}{c}\text { Provox } \\
\mathbf{2}\end{array}$ & $\begin{array}{c}\text { Blom- } \\
\text { Singer }\end{array}$ & $\begin{array}{c}\text { No } \\
\text { Valve }\end{array}$ & Total \\
\hline Yes & 10 & 26 & 2 & 8 & 41 \\
\hline No & 13 & 33 & 0 & 0 & 49 \\
\hline Total & 23 & 59 & 2 & 8 & 90 \\
\hline
\end{tabular}

Table 9: Complications in different VP used as reported by Calder et al $\mathrm{p}$ value $>0.005$ (retrospective review over a 10 year duration on patients with TL and TEP with VP insertion from January 1993 to December 2002 at Gartnavel General and Stobhill Hospitals) ${ }^{23}$

\begin{tabular}{|l|c|}
\hline Complication of TEP & Number of patients \\
\hline Granulations & 20 \\
\hline Enlarged fistula & 16 \\
\hline Loss of valve & 16 \\
\hline Voice loss & 7 \\
\hline Closure of fistula & 2 \\
\hline Dysphagia & 6 \\
\hline Infection & 1 \\
\hline Leakage & 2 \\
\hline Second fistula & 1 \\
\hline
\end{tabular}

Table 10: Complications of TEP as reported by Calder et al23 


\begin{tabular}{|l|c|c|c|}
\hline Complication & $\begin{array}{c}\text { Primary } \\
\text { TEP (\%) }\end{array}$ & $\begin{array}{l}\text { Secondary } \\
\text { TEP (\%) }\end{array}$ & $\begin{array}{c}\text { P- } \\
\text { Value }\end{array}$ \\
\hline PCF & 50 & 0 & $0.006^{*}$ \\
\hline PE stenosis & 10 & 2 & 0.31 \\
\hline $\begin{array}{l}\text { Wound/stomal } \\
\text { breakdown }\end{array}$ & 35 & 3 & 0.49 \\
\hline Wound infection & 15 & 1 & 0.59 \\
\hline TEP site leakage & 5 & 1 & 0.46 \\
\hline CP spasm & 5 & 1 & 0.46 \\
\hline Stomal stenosis & 0 & 0 & 1.00 \\
\hline
\end{tabular}

Table 11: Percentage of complications in primary and secondary TEP (PCF, p value 0.06) as reported by Emerick et al (retrospective review of a prospective cohort of patients. Patients were selected from the University of Michigan organ preservation protocols taken place between 1998 and 2005. Study focused on the complications of patients with primary and secondary TEP following induction and concurrent chemoradiation). ${ }^{24}$

Tables 12-15 provide a meaning full comparison of the selected studies

\begin{tabular}{|l|c|c|c|c|c|}
\hline Study & $\begin{array}{c}\text { Number of } \\
\text { participants }\end{array}$ & Mean age & $\begin{array}{c}\text { Age range } \\
\text { (Years) }\end{array}$ & $\begin{array}{c}\text { Males } \\
\mathbf{( \% )}\end{array}$ & $\begin{array}{c}\text { Females } \\
\text { (\%) }\end{array}$ \\
\hline $\begin{array}{l}\text { Dayangku } \\
\text { Norsuhazenah } \text { et al }\end{array}$ & 22 & 62.1 & $41-79$ & 95.5 & 4.5 \\
\hline Cheng et al & 68 & 59 & $31-82$ & 75.0 & 25.0 \\
\hline Makitie et al & 95 & 63.5 & $38-88$ & 93.0 & 7.0 \\
\hline Boscolo-Rizzo et al & 93 & 63 & $39-86$ & 93.5 & 6.5 \\
\hline Imre et al & 47 & 62.8 & $41-80$ & & \\
\hline Calder et al & 100 & 61 & $44-82$ & 74.0 & 26.0 \\
\hline Emerick et al & 30 & 62.2 - Primary TEP & - & 90.0 & 10.0 \\
\hline
\end{tabular}

Table 12: Retrospective study information for the seven selected studies

\begin{tabular}{|l|c|c|}
\hline & \multicolumn{2}{|c|}{$\begin{array}{c}\text { Percentage of patients } \\
\text { undergoing procedure (\%) }\end{array}$} \\
\hline \multicolumn{1}{|c|}{ Study } & Primary & Secondary \\
\hline $\begin{array}{l}\text { Dayangku } \\
\text { Norsuhazenah } \text { et al }\end{array}$ & 18.0 & 82.0 \\
\hline Cheng et al & 75.0 & 25.0 \\
\hline Makitie et al & 81.0 & 18.0 \\
\hline Boscolo-Rizzo et al & 80.6 & 19.3 \\
\hline Imre et al & 0.0 & 100.0 \\
\hline Calder et al & 90.0 & 8.0 \\
\hline Emerick et al & 66.7 & 33.3 \\
\hline
\end{tabular}

Table 13: Number of patients undergoing primary or secondary TEP in each of the seven studies

\begin{tabular}{|l|c|c|}
\hline & \multicolumn{2}{|c|}{$\begin{array}{c}\text { Overall complications across } \\
\text { primary and secondary TEP (\%) }\end{array}$} \\
\hline \multicolumn{1}{|c|}{ Study } & $\begin{array}{c}\text { Surgical } \\
\text { complication }\end{array}$ & $\begin{array}{c}\text { Prosthesis- } \\
\text { related } \\
\text { complication }\end{array}$ \\
\hline $\begin{array}{l}\text { Dayangku } \\
\text { Norsuhazenah } \text { et al }\end{array}$ & 32.7 & 77.3 \\
\hline Cheng et al & 39.7 & 42.6 \\
\hline Makitie et al & - & 66.0 \\
\hline Boscolo-Rizzo et al & 25.8 & - \\
\hline Imre et al & \multicolumn{2}{|c|}{42.0} \\
\hline Calder et al & 43.0 & \\
\hline Emerick et al & \multicolumn{2}{|c|}{-} \\
\hline
\end{tabular}

Table 14: Reported percentages of surgical and prosthesis-related complications 


\begin{tabular}{|l|c|c|c|c|}
\hline \multicolumn{1}{|c|}{ Study } & \multicolumn{2}{c|}{ Primary } & \multicolumn{2}{c|}{ Secondary } \\
\hline & Surgical (\%) & $\begin{array}{c}\text { Prosthesis } \\
\text { related (\%) }\end{array}$ & Surgical (\%) & Prosthesis related (\%) \\
\hline Dayangku Norsuhazenah et al & Equal incidence & 50.0 & Equal incidence & 38.9 \\
\hline Cheng et al & 43.1 & 47.1 & 29.4 & 29.4 \\
\hline Boscolo-Rizzo et al & 20.3 & - & 16.7 & - \\
\hline Imre et al & - & - & 25.3 & 36.0 \\
\hline $\begin{array}{l}\text { Calder } \text { et al } \\
\text { *Fisher's exact test } \mathrm{p}=0.0015\end{array}$ & \multicolumn{2}{|c|}{41.4} & 0.0 & 0.0 \\
\hline
\end{tabular}

Table 15: Reported complications in primary and secondary TEP groups

\section{DISCUSSION}

From the selected studies we can see that they are all retrospective in nature. This study has reported the results and findings of seven reviews in order to ascertain any trends or patterns amongst the complications in primary and secondary TEP. More importantly grouping the studies and using similar parameters has allowed us to create a more holistic and representative picture regarding the complications thus providing a more accurate comparison of the effect of the timing of TEP on complications. Additionally, the number of participants across all trials was small with the maximum being 100 (Table 12). Mean age across all seven studies ranged from 59-64.1 years. Males made up the larger percentage of participants across the trials, with all seven studies recruiting $74 \%$ or more males. This is reflective of the higher incidence of laryngeal cancers amongst men; however might not be reflective of the general population. Additionally, the percentage of patients undergoing primary TEP versus secondary TEP varied depending on the criteria of each study. Some studies had higher percentages of primary TEP whereas others had the opposite. In total five out of the seven studies had higher percentages of primary TEP, since these studies were retrospective this finding supports the recent increase over the last decade in a preference amongst ENT surgeons in opting for primary TEP. More importantly selection bias (preference) has led to an inconsistency in numbers when comparing both procedures. This has made it increasingly difficult to properly assess and compare both procedures as there are more patients undergoing primary TEP rather than secondary.

From the results we can see that the complications of TEP are best divided into two separate categories, each one representing the origin of the problem (surgical and prosthesis related). Identifying the complication in such a manner allows the clinician to manage the patient appropriately. Surgical and prosthesis related complications occurred in both primary and secondary TEP groups. The nature of complications was similar across both types of TEP. When looking at surgical complications, problems with the fistula (enlargement, closure, secondary) were commonly reported on, with Imre et al recording an occurrence of $19.1 \%$ in patients with secondary TEP 22 (Table 7). This was similar to Calder $e a^{23}$ who reported that an enlarged fistula occurred in 20 patients (16.8\%) undergoing either TEP and by Dayangku Norsuhazenah et $a l^{19}$ who suggested an occurrence in three patients (14\%). Tracheostomal stenosis was another common surgical complication of TEP regardless of the timing with Dayangku Norsuhazenah et al ${ }^{19}$ reporting an occurrence of $50 \%$. Among the other surgical complications included mediastinitis, cervical spine fractures, cervical cellulitis, peritracheostomal infection and abscesses. Similarly, the timing of the procedure did not have any effect on the type of prosthesis related complications suffered across both groups. Leakage around the prosthesis was reported in six out of the seven studies with the Dayangku Norsuhazenah et $a l^{19}$ reporting an occurrence of $64 \%$ followed by Makitie $e t a l^{20}$ who suggested a $51.8 \%$ occurrence across both groups. Granulation tissue was reported in four out of the seven studies with the highest percentage of occurrence being $21.1 \%$ of in Calder et al ${ }^{23}$ followed by $18 \%$ as suggested by Dayangku Norsuhazenah et al. ${ }^{19}$ Lastly, displacement/obstruction of prosthesis was also mentioned across the studies with a $32 \%$ occurrence across both groups noted by Dayangku Norsuhazenah et al. ${ }^{19}$ Rarer complications included dysphagia and voice loss as reported by Calder $e t \mathrm{al}^{23}$

When looking at surgical and prosthesis-related complications, there seemed to be some inconsistencies present in the reporting of each, as some studies presented an overall complication of TEP whereas others categorized them. Dayangku Norsuhazenah et $a l^{19}$ and Makitie et $a^{20}$ suggest that prosthesis-related complications have a higher incidence as compared with surgical, however such an assumption cannot be made on the basis of such a small number of studies. More importantly Imre $e t a l^{22}$ and Calder et $a l^{23}$ show an overall complication rate of $42 \%$ and $45 \%$ respectively (Table 14 ). These numbers are in line with what has been recorded in literature between 10 and 52 percent. ${ }^{25,26}$ Such high numbers of post-operative complications suggest that addressing these should be among the primary aims of assessing the quality of surgical 
voice restoration attained. This finding emphasizes the notion that earlier voice restoration should not be the sole factor deciding the outcome of this intervention, rather a combination of both.

Similarly when trying to compare the complication rate between primary and secondary TEP there seems to be variation present. Table 15 shows an equal incidence of surgical complications between the two groups as reported by Dayangku Norsuhazenah et al. ${ }^{19}$ This is not the case when looking at the prosthesis related complications as Table 15 shows a higher percentage in primary TEP as compared with secondary TEP in the same study. This can further be supported by the other results which show a general trend towards a higher percentage of complications among primary TEP patients. Boscolo-Rizzo et $a l^{21}$ had remarkable results, with no patients undergoing secondary TEP suffering from complications as compared with $41 \%$ receiving a primary TEP. Such results further support the claim that secondary TEP provides a lesser chance of suffering from complications as compared with primary. This was supported statistically by Calder et $a l^{23}$ as they found a significant difference in complication rates between primary and secondary TEP ( $p=0.0015$, Table 15). Alongside this, Emerick et al ${ }^{24}$ have statistically confirmed a significant difference between the groups with regards to complications of pharyngocutaneous fistula (PCF) $(\mathrm{p}=0.006$, Table 11). It is important to note that PCF increase the morbidity of patients. ${ }^{24}$ They can lead to increased hospitalisations, delay in oral intake and life threatening complications such as a carotid blowout. ${ }^{24}$ Additionally the study concluded that co morbidities did not have any effect on the rate of complications of both groups. This was found to be contradicted by a study published in $1985^{27}$ which concluded that diabetes and documented oesophageal strictures are risk factors which increase the risk of post-operative complications.

Interestingly when looking at VP and their effects on the rates of complication Calder et $a^{23}$ compared three popular valves commonly used in the market (Provox 1, Provox 2 and Blom Singer). It concluded that the use of each of these did not create a significant difference in the rate of complications ( $p>0.05$, Table 9$)$. This is an important finding with regards to post-operative complications and therefore stresses on other factors such as longevity, voice quality etc to be the judge of the success rates of these valves.

It is important to note several limitations faced by us when conducting this systematic review. In order to provide a more accurate and better understanding of the complication rates it is worth carrying out a meta-analysis of the current literature. This will provide more reliable results and help solidify risk factors as well as common complications in order to create an individualised care pathway for each patient opting for surgical voice restoration. Having suggested this, it is also important to stress the lack of similarity in criteria used between previous studies thus making it harder to easily compare the findings. In order to tackle this issue it might be worth carrying out prospective randomized control trials on this topic rather than retrospective reviews. Even though they might be a costlier option they will provide more accurate data, larger number of patients and can adopt similar parameters hence making a meta-analysis more plausible. There also seems to be some inconsistencies present in the classification of problems between the studies (surgical or prosthesis-related). This has led to some confusion and has made it increasingly difficult to compare studies. A universally accepted classification can help solve this issue and provide better comparisons.

Even though there has been extensive research done on the complications of primary and secondary TEP, there is no clear cut evidence suggesting which one leads to fewer problems. Studies so far have been contradicting and a lack of similar parameters amongst them has made it hard to apply a meta-analysis. It could be argued that results are leaning more towards the idea that secondary TEPs produce fewer complications however the difference is not significant enough to gain enough weighting to challenge the benefits of early voice restoration achieved by primary TEP. Alongside this, an absence of recommendations regarding the optimal time for performing TEP suggests that more work needs to be done on this topic. A lack of clarity in the complications has meant that the weight of early voice restoration and speech quality is seen as more than that of the complications. This might explain why primary TEP has become more fashionable in recent times however this might not be the best choice, as one might be sacrificing long term gains for short term benefits. It is imperative that a greater understanding of the similarities and differences in complications between the two procedures is gained as this will lead to improvements in the post-operative results of these procedures. After having conducted this study our recommendations for future research on this topic include carrying out prospective studies with similar parameters, applying meta analyses and trying to create a universally accepted classification of which complications can be considered surgical or prosthesis-related.

\section{REFERENCES}

1. Netter Images. Pharynx median section. Available at: www.netterimages.com/pharynx-median-sectionlabeled-multiple-publications-general-anatomyfrank-h-netter-4876.html. (accessed 12.6.18).

2. Martini FHNJ. Fundamentals of anatomy and physiology. 7th ed. San Francisco: Pearson/Benjamin Cummings, 2009.

3. About Cancer. Head and neck cancer images and anatomy. Available at: http://www.aboutcancer.com/ anatomy_glottis.gif (accessed 12.6.18)

4. Wiegand S. Evidence and evidence gaps of laryngeal cancer surgery. GMS Current Topics in Otorhinolaryngology, Head and Neck Surgery. 2016;15:Doc03.

5. EUCAN. Laryngeal Cancer. 2012 [cited 2017]; Available from: https://tinyurl.com/yc615fk4 (accessed 12.6.18)

6. Cattaruzza MS, Maisonnueve P, Boyle P. Epidemiology of laryngeal cancer. Eur J Cancer B Oral Oncol. 1996;32B(5):293-305

7. NICE. Treatment of upper aerodigestive tract cancer. 2016 updated 2018. Available at: https:// pathways.nice.org.uk/pathways/upper-aerodigestive- 
tract-cancer\#path=view $\% 3 \mathrm{~A} /$ pathways/upperaerodigestive-tract-cancer/treatment-of-upperaerodigestive-tract-cancer. $x m l \& c o n t e n t=v i e w-$ node\%3Anodes-larynx. (accessed 12.6.18)

8. Rafferty MA, Fenton JE, Jones AS. The history, aetiology and epidemiology of laryngeal carcinoma. Clinical Otolaryngology \& Allied Sciences. 2001;26(6):442-6.

9. Ceachir O, Hainarosie R, Zainea V. Total laryngectomy - past, present, future. Maedica. 2014;9(2):210-6. Epub 2015/02/24.

10. Breaks A. Critical review: effect of primary versus secondary tracheoesophageal puncture (TEP) on voice rehabilitation in patients who have undergone total laryngectomy. 2012. Available at: http:// speechandhearingbc.ca/professional/resources/ speech-language-links/voice/ (accessed 12.6.18)

11. Deschler DG, Bunting GW, Lin DT, Emerick K, Rocco J. Evaluation of voice prosthesis placement at the time of primary tracheoesophageal puncture with total laryngectomy. The Laryngoscope. 2009;119(7):1353-7. Epub 2009/06/10.

12. Roxburgh J, Perry A. Use of a "hands-free" tracheostoma valve in patients with laryngectomy and tracheoesophageal puncture. The Annals of Otology, Rhinology, and Laryngology. 2004;113(7):565-70. Epub 2004/07/28.

13. Deschler DG, Emerick KS, Lin DT, Bunting GW. Simplified technique of tracheoesophageal prosthesis placement at the time of secondary tracheoesophageal puncture (TEP). The Laryngoscope. 2011;121(9):1855-9. Epub 2011/06/22.

14. Lewin JS, Portwood MA, Wang Y, Hutcheson KA. Clinical application of the Provox NiD voice prosthesis: a longitudinal study. The Laryngoscope. 2014;124(7):1585-91. Epub 2013/12/20.

15. Lewin JS. Hutcheson KA. General Principles of rehabilitation of speech, voice, and swallowing function after treatment of head and neck cancer. In: Harrison LB et al. Head and neck cancer: a multidisciplinary approach. Philadelphia: Lippincott, Williams and Wilkins. 2009:168-77.

16. Singer MI, Blom ED. An endoscopic technique for restoration of voice after laryngectomy. The Annals of Otology, Rhinology, and Laryngology. 1980;89(6 Pt 1):529-33. Epub 1980/11/01.

17. Cheng E, Ho M, Ganz C, Shaha A, Boyle JO, Singh B, et al. Outcomes of primary and secondary tracheoesophageal puncture: a 16-year retrospective analysis. Ear, Nose, \& Throat Journal. 2006; 85(4): 262, 4-7. Epub 2006/05/16.

18. Maves MD, Lingeman RE. Primary vocal rehabilitation using the Blom-Singer and Panje voice prostheses. The Annals of Otology, Rhinology, and Laryngology. 1982; 91(4 Pt 1): 458-60. Epub 1982/07/01.

19. Dayangku Norsuhazenah PS, Baki MM, Mohamad Yunus MR, Sabir Husin Athar PP, Abdullah S. Complications following tracheoesophageal puncture: a tertiary hospital experience. Annals of the Academy of Medicine, Singapore. 2010;39(7):565-4. Epub 2010/08/11.
20. MakitieAA,Niemensivu R, JuvasA,Aaltonen LM, Back L, Lehtonen H. Postlaryngectomy voice restoration using a voice prosthesis: a single institution's tenyear experience. The Annals of Otology, Rhinology, and Laryngology. 2003;112(12):1007-10. Epub 2004/01/02.

21. Boscolo-Rizzo P, Zanetti F, Carpené S, Da Mosto MC. Long-term results with tracheoesophageal voice prosthesis: primary versus secondary TEP. European Archives of Oto-Rhino-Laryngology. 2008;265(1):737 .

22. Imre A, Pinar E, Calli C, Sakarya EU, Ozturkcan S, Oncel S, et al. Complications of tracheoesophageal puncture and speech valves: retrospective analysis of 47 patients. Kulak burun bogaz ihtisas dergisi : KBB $=$ Journal of ear, nose, and throat. 2013;23(1):15-20. Epub 2013/03/26.

23. Calder N, MacAndie C, MacGregor F. Tracheoesophageal voice prostheses complications in north Glasgow. The Journal of Laryngology and Otology. 2006;120(6):487-91. Epub 2006/06/15.

24. Emerick KS, Tomycz L, Bradford CR, Lyden TH, Chepeha DB, Wolf GT, et al. Primary versus secondary tracheoesophageal puncture in salvage total laryngectomy following chemoradiation. Otolaryngology-Head and Neck Surgery. 2009; 140(3):386-90.

25. Van Den Hoogen FJA, Oudes MJ, Hombergen G, Nijdam HF, Manni JJ. The Groningen, Nijdam and Provox voice prostheses: a prospective clinical comparison based on 845 replacements. Acta OtoLaryngologica. 1996;116(1):119-24.

26. Prichard AJ, Powell A, Samuel PR, Stafford FW. Surgical voice restoration: the Sunderland experience. Journal of the Royal College of Surgeons of Edinburgh. 1994;39(6):355-9. Epub 1994/12/01.

27. Silver FM, Gluckman JL, Donegan JO. Operative complications of tracheoesophageal puncture. The Laryngoscope. 1985;95(11):1360-2. Epub 1985/11/01.

Correspondence to: Basil Khan, b.khan2@lancaster.ac.uk or shadaba.ahmed@mbht.nhs.uk 